\title{
CCL18 synergises with high concentrations of glucose in stimulating fibronectin production in human renal tubuloepithelial cells
}

Rosa M. Montero*, Gurjeet Bhangal, Charles D. Pusey, Andrew H. Frankel and Frederick W. K. Tam

\begin{abstract}
Background: Diabetic nephropathy is the leading cause of end stage kidney disease worldwide. The pathogenesis of this disease remains elusive and multiple factors have been implicated. These include the effects of hyperglycaemia, haemodynamic and metabolic factors, and an inflammatory process that stimulates cellular signalling pathways leading to disease progression and severe fibrosis. Fibronectin (Fn) is an important protein of the extracellular matrix that is essential in fibrosis and its presence in increased amounts has been identified in the kidney in diabetic nephropathy.

Methods: Proximal tubuloepithelial (HK-2) cells were stimulated with high glucose (30 mM D-glucose) or glycated albumin $(500 \mathrm{\mu g} / \mathrm{mmol})+4 \mathrm{mM}$ D-glucose or their controls, Mannitol (26 mM $+4 \mathrm{mM} \mathrm{D-glucose)}$ and $4 \mathrm{mM}$ D-glucose, respectively. Following $48 \mathrm{~h}$ of stimulation the supernatant was collected and MTT [3-(4,5-dimethylthiazole2,5-diphenyltetrazolium bromide] assay performed to assess cell viability. HK-2 cells were also stimulated in the above environments with recombinant CCL18 (rCCL18) or MCP-1 (rMCP-1) for $48 \mathrm{~h}$ with quantification of Fn levels using ELISA.

Results: Co-stimulation of HK-2 cells with high concentrations of glucose and rCCL18 significantly increased Fn $(p<0.001)$, in comparison to high concentrations of glucose alone. HK-2 cells stimulated with glycated albumin consistently produced Fn and this did not alter following co-stimulation with rCCL18 or rMCP-1.

Conclusion: This study demonstrates how stimulation with a specific chemokine CCL18 in high glucose upregulates the production of Fn from proximal tubuloepithelial cells. This may be relevant to the development of renal fibrosis in diabetic nephropathy
\end{abstract}

Keywords: CCL18, MCP-1, Fibronectin, Diabetic nephropathy, HK-2 cells

\section{Background}

Diabetic nephropathy (DN) is an important complication of diabetes mellitus that despite current treatment often results in the development of chronic kidney disease and end stage kidney disease. The time course for progression is variable and has traditionally been associated with increasing proteinuria [1]; however, this marker may now be less useful as ACEi/ARB may cause reduction in proteinuria but not necessarily a halt in disease progression [2]. Glomerular and tubulointerstitial

\footnotetext{
* Correspondence: rosa_montero@hotmail.com

Renal and Vascular Inflammation Section, Department of Medicine, Imperial

College London, Hammersmith Hospital, London W12 0NN, UK
}

fibrosis are seen in renal biopsies of those with $\mathrm{DN}$ and may be a better marker of decline in renal function [3]. Understanding the mechanisms of fibrosis is therefore important. Fibronectin (Fn) is a protein found in the extracellular matrix and has a number of binding sites that may bind surfaces containing collagen and heparin. The production of Fn has been described in experimental $\mathrm{DN}$ as one of the extracellular matrices that contribute to the development of glomerulosclerosis [4]. Fn has also been reported to be increased in the glomeruli of patient and animal models of DN [5] and is an important marker of fibrosis. The effect of the diabetic milieu on Fn production by intrinsic renal cells is not fully understood. 
Fibronectin production is upregulated in immortalised mouse podocytes stimulated with high glucose in-vitro, supporting the profibrotic effects of the diabetic environment [6-8]. There are reports of decreased Fn production when podocytes are stimulated with transforming growth factor- $\beta$ (TGF- $\beta$ ) [9]; however, the effect of this in a diabetic environment is unclear. Podocytes treated with insulin appear to be protected from apoptosis via anti-angiotensin 2 mechanisms [10]. The protective effect of insulin on podocytes has been reported to be limited following stimulation with albumin that results in an increase in Fn production and apoptosis [10]. A recent study looking into the effects of toll-like receptor4 in a mouse model of DN has reported an upregulation of TGF- $\beta$ and Fn genes when mouse tubuloepithelial cells were cultured in high glucose [11].

Fn levels have been reported to increase in human proximal tubuloepithelial cells exposed to high glucose compared with normal glucose in-vitro [12]. This finding has been reversed using the compound Fasudil, a Rhoassociated coiled-coil forming protein serine/threonine kinase(ROCK) inhibiting renal fibrosis. However, the effect of cytokines on Fn production in human proximal tubuloepithelial cells in diabetic conditions is unclear. Increasingly, studies suggest that proteinuria and loss of renal function correlate closely with the severity of underlying tubulointerstitial lesions [13]. Other studies report that tubulointerstitial cells play a role in epithelial-myofibroblast transdifferentiation (EMT) in DN [12]. In addition, Tervaert's histopathological classification for DN reflects an appreciation of the role of the tubulointerstitium in DN [3]. We investigated the ability of HK-2 cells to produce Fn and whether this is affected by stimulation with high glucose or glycated albumin, as found in the diabetic milieu. We then examined the effect of costimulation with recombinant chemokines (CCL18, MCP-1) that have previously been detected in the urine of patients with $\mathrm{DN}$.

There are numerous studies reporting the importance of inflammation in the progression and development of DN [14]. The diabetic milieu has been reported to induce the production of inflammatory molecules that stimulate signalling cascades facilitating migration of inflammatory cells [14-16]. Macrophage infiltration has been reported in the renal biopsies of patients with diabetic nephropathy (DN) [3, 17]. Cytokines can orchestrate the migration of inflammatory cells into renal tissues [14] with some pro-inflammatory cytokines such as tumour necrosis factor- $\alpha$, interleukin-1 (IL-1), IL-6, IL-18 contributing to renal tubular damage and progression of DN [18-20].

A number of studies have reported an association between urinary chemokines/cytokines and the progression of $\mathrm{DN}$, in particular CCN2/MCP-1 (monocyte chemoattractant protein-1) [21]. Urinary CTGF has been reported to correlate with the progression of $\mathrm{DN}$ [22]. Our group has previously reported $\mathrm{C}-\mathrm{C}$ chemokine ligand 18 (CCL18/PARC) urinary levels to be raised in proteinuric diabetic patients compared to a non-diabetic proteinuric renal disease cohort [23]. Urinary cytokines may arise from intrinsic renal cells or infiltrating inflammatory cells.

This study examines the effect of the diabetic milieu on Fn production by HK-2 cells in-vitro. In addition, the effects of stimulation with recombinant CCL18 (rCCL18) or recombinant MCP-1 (rMCP-1) on Fn production from HK-2 cells are reported.

\section{Methods \\ Materials}

$30 \mathrm{mM} \mathrm{D}$-glucose was used as high glucose concentration for the following experiments, with Mannitol used as the osmotic control (26 mM $+4 \mathrm{mM}$ of D-glucose). Glycated albumin (A8301, Sigma, Gillingham, UK) was used at a concentration of $500 \mu \mathrm{g} / \mathrm{ml}+4 \mathrm{mM}$ D-glucose, with physiological $4 \mathrm{mM}$ D-glucose used as its control. The Fn ELISA was carried out using rabbit anti-human Fn polyclonal Ab for capture (F3648, Sigma, Gillingham, UK) and biotinylated murine anti-human Fn monoclonal Ab (F7387, Sigma, Gillingham, UK) for detection. Fn derived from human plasma was used as the antigen for the standard curve (range 1.95-2000 pg/ml) (F0895, Sigma, Gillingham, UK).

Recombinant human CCL18 (394-PA, R\&D systems, Abingdon, UK) and MCP-1 (279-MC, R\&D systems, Abingdon, UK) were reconstituted according to the manufacturer's instructions. Following dose response experiments, HK-2 cells were stimulated with recombinant CCL18 or rMCP-1 at a concentration of $20 \mathrm{ng} / \mathrm{ml}$ for $48 \mathrm{~h}$. Fn levels were subsequently measured from the cell supernatant using ELISA.

\section{Cell culture}

HK-2 cells are an immortalised proximal tubuloepithelial cell line from normal adult human kidney that was a gift from Professor Roger Mason, Imperial College London, London, UK. Cells were grown at $37{ }^{\circ} \mathrm{C}$ in T75 tissue culture flasks until $70 \%$ confluent and then $5 \times 10^{6}$ cells were seeded into 6 well plates and maintained in keratinocyte media supplemented with bovine pituitary extract and epidermal growth factor (Life Technologies, GIBCO), 5\% FCS, penicillin and streptomycin. Once the cells reached $70 \%$ confluence in the 6 well plates, they were maintained for a further $24 \mathrm{~h}$ before their media was changed to RPMI 1640 supplemented with $1000 \mathrm{U} / \mathrm{ml}$ penicillin, $100 \mathrm{~g} / \mathrm{ml}$ streptomycin and $2 \mathrm{mM}$ glutamine without serum. 
Proximal tubuloepithelial cells are intrinsic renal cells that may be associated with release of cytokines in the urine. Pilot studies were performed using HK-2 cells stimulated with cytokines (Montero, unpublished data) previously identified in the urine of patients with $\mathrm{DN}$ [21, 23]. These studies suggested an interaction between HK-2 cells in the diabetic environment stimulated with rCCL18 or rMCP-1, hence informing the design of this study.

The glucose condition of choice (see above) was placed in each well alone $(n=6)$ or co-stimulated with rCCL18 $(n=6)$ or rMCP-1 $(n=6)$ for 48 h. Each condition was replicated in 6 wells for each experiment. Each experiment was repeated three times to ensure reproducible results. The plates were incubated and the supernatants were collected at $48 \mathrm{~h}$.

\section{Analysis of samples}

Supernatants were collected from the 6 well plates and centrifuged to remove cell debris. The supernatants were stored at $-80{ }^{\circ} \mathrm{C}$ for later analysis. The [3-(4,5-dimethylthiazole-2,5-diphenyltetrazolium bromide], (MTT) assay (Sigma, UK) was performed on the 3 wells for each cultured condition to assess cell viability and read on the ELISA plate reader at $550 \mathrm{~nm}$. Direct cell count was performed using Trypan blue exclusion assay (Sigma, UK).

\section{Enzyme-linked Immunoabsorbent Assay (ELISA)}

The fibronectin in the cell culture supernatant samples was quantified by ELISA. Briefly Fn capture Ab was used to coat a 96 well Nunc plate overnight at $4{ }^{\circ} \mathrm{C}$. The plate was washed three times and incubated in blocking solution for $1 \mathrm{~h}$. The plate was washed thrice and the samples and standard applied, leaving the plate to incubate overnight at $4{ }^{\circ} \mathrm{C}$. The plate was washed three times and incubated for $1 \mathrm{~h}$ with the detection Ab. The plate was washed and the Streptavidin, Substrate and Stop solution steps were as per standard ELISAs. The ELISA plate reader was used at $492 \mathrm{~nm}$ wavelength. Intra and interassay variability was $5.4 \%$ and $8.7 \%$, respectively.

\section{Statistics}

Graph Pad PRISM software (version 4) was used to perform data analysis. Fibronectin concentration was analysed using Kruskal-Wallis with Dunn's post analysis for multiple comparisons. MTT assay and direct cell count with Trypan blue exclusion assay results were presented as mean \pm SD and assessed using Analysis of variance with Bonferroni's correction for multiple comparisons. $P$ value $<0.05$ compared with the control were considered as statistically significant.

\section{Results}

Diabetic milieu

Effect of high concentration of glucose on fibronectin production

Fn was detected in the supernatant of HK-2 cells following $48 \mathrm{~h}$ stimulation with high glucose with similar levels seen in the osmotic control mannitol (median $6948 \mu \mathrm{g} / \mathrm{ml}$ (range 3414-11250) and median $4883 \mu \mathrm{g} / \mathrm{ml}$ (range 2971-5405), respectively, non-significant) (Fig. 1).

\section{Effect of glycated albumin on fibronectin production}

Fn was detected in the supernatant of HK-2 cells following $48 \mathrm{~h}$ stimulation with physiological glucose $(4 \mathrm{mM}$ D-glucose) at a median concentration of $6813 \mu \mathrm{g} / \mathrm{ml}$ (range 6112-8210) and when stimulated with glycated albumin in the presence of $4 \mathrm{mM} \mathrm{D}$-glucose at median Fn levels of $7976 \mu \mathrm{g} / \mathrm{ml}$ (range 5998-10410). Differences were not significant (Fig. 1).

\section{Recombinant cytokines \\ Effect of co-stimulation with rCCL18 on fibronectin production}

There was a significant rise in the levels of Fn in the supernatant of HK-2 cells following stimulation with rCCL18 in the presence of high concentrations of glucose compared to high concentrations of glucose only $(p<0.001)$ (Fig. 1). The Fn levels were not significantly

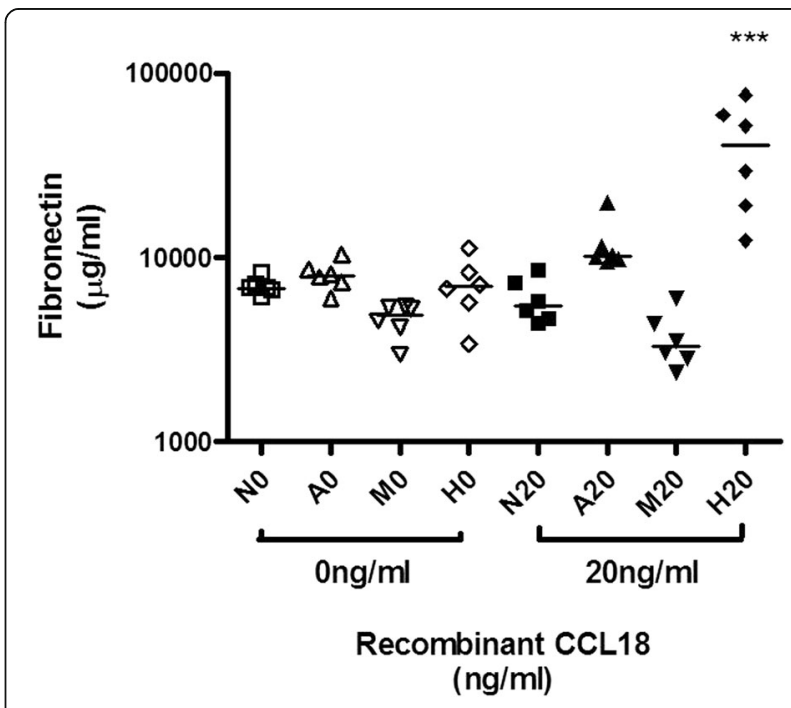

Fig. 1 The production of fibronectin (Fn) by HK-2 cells stimulated with recombinant CCL18 for $48 \mathrm{~h}$ in a diabetic milieu. A significantly higher concentration of Fn was produced by HK-2 cells stimulated with recombinant CCL18 in high concentration of glucose in comparison to CCL18 only or high glucose concentration only. $P<0.001$. Key: $\mathrm{NO}=$ physiological glucose, $\mathrm{A} 0=$ glycated albumin, $\mathrm{M0}=$ mannitol, $\mathrm{HO}=$ high glucose, $\mathrm{N} 20=$ physiological glucose $+20 \mathrm{ng} / \mathrm{ml} \mathrm{CCL18,}$ A20 = glycated albumin $+20 \mathrm{ng} / \mathrm{ml}$ CCL18, M20 = mannitol $+20 \mathrm{ng} / \mathrm{ml}$ CCL18, H20 = high glucose $+20 \mathrm{ng} / \mathrm{ml} \mathrm{CCL18}$ 
raised in glycated albumin conditions with rCCL18, in comparison to glycated albumin only at $48 \mathrm{~h}$.

\section{Effect of co-stimulation with rMCP-1 on fibronectin production}

There were no significant differences in the Fn levels in the supernatant of HK-2 cells cultured with glycated albumin or high glucose when stimulated with rMCP-1 for $48 \mathrm{~h}$, compared with those without additional rMCP-1 (Fig. 2).

\section{Cell viability assays}

MTT assay showed an overall decrease in cell viability of HK-2 cells cultured in glycated albumin that did not alter following co-stimulation with cytokines. There were an increased number of surviving cells in high glucose conditions, but the difference did not reach statistical significance (Tables 1 and 2). We further investigated the number of viable cells in cells stimulated with high glucose concentration with or without recombinant stimulation with CCL18 using trypan blue exclusion assay. We found that the number of viable cells was not signficantly different between stimulation with high concentration of glucose only vs manitol osmolarity control and recombinant CCL18 vs high concentration of glucose and recombinant CCL18 (Table 2). The number of viable cells cultured with mannitol and normal glucose concentration was lower than in the other conditions.

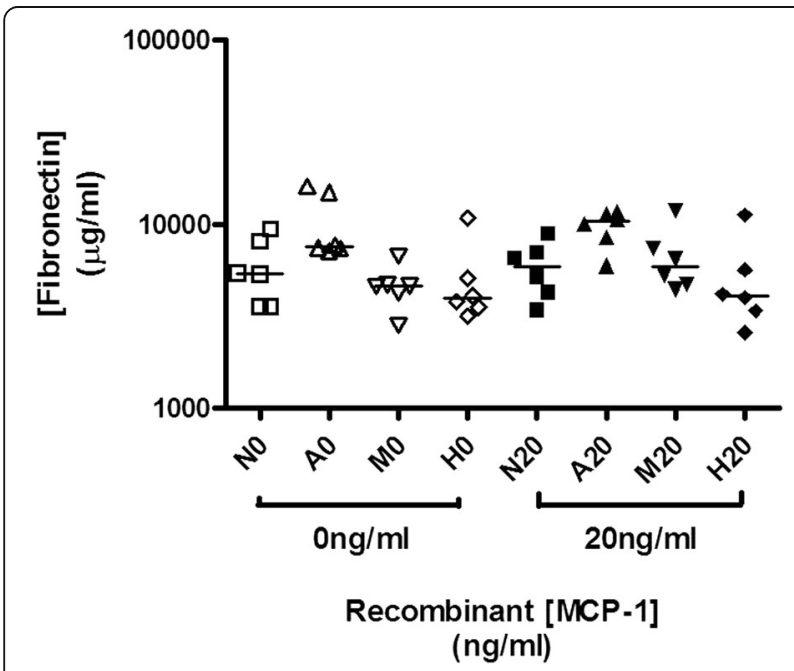

Fig. 2 The production of fibronectin by HK-2 cells stimulated with recombinant MCP-1 for $48 \mathrm{~h}$ in a diabetic milieu. There were no any significant differences in Fn production in HK-2 cells stimulated under different conditions. Key: $\mathrm{NO}=$ physiological glucose, $\mathrm{AO}=$ glycated albumin, $\mathrm{MO}=$ mannitol, $\mathrm{HO}=$ high glucose, $\mathrm{N} 20=$ physiological glucose $+20 \mathrm{ng} / \mathrm{ml} \mathrm{MCP-1,} \mathrm{A20} \mathrm{=} \mathrm{glycated} \mathrm{albumin}+20 \mathrm{ng} / \mathrm{ml}$ MCP-1, M20 = mannitol $+20 \mathrm{ng} / \mathrm{ml} \mathrm{MCP-1,} \mathrm{H20} \mathrm{=} \mathrm{high} \mathrm{glucose}+$ $20 \mathrm{ng} / \mathrm{ml}$ MCP-1
In conclusion, there is increased production of fibronectin in HK2 cells stimulated with combination of recombinant CCL18 and high glucose concentration, in comparison to high concentration of glucose only or recombinant CCL18 and mannitol control with normal glucose concentration. The number of viable HK2 cells were not significantly different when assessed by both MTT and trypan blue exclusion assays.

\section{Discussion}

This study demonstrates that HK-2 cells in high glucose co-stimulated with rCCL18 in-vitro increase the production of Fn compared to a high concentration of glucose only. This result cannot be explained by differences in cell viability, with no significant difference seen by direct cell count using trypan blue exclusion assay or MTT assay. Increased Fn production was not seen following co-stimulation with rMCP-1 or with glycated albumin. The MTT assay showed an overall decrease in cell viability of HK-2 cells in glycated albumin that did not alter with co-stimulation with rCCL18 or rMCP-1. Previous studies have reported an increase in Fn production between physiological and high glucose that was not seen in our present study [12]. Gu and colleagues measured fibronectin following stimulation with a much higher concentration $(60 \mathrm{mmol} / \mathrm{L})$ of D-glucose on HK-2 cells for a long duration of $72 \mathrm{~h}$, and thus the difference in time course may explain the discrepancy between our findings.

It is established in DN that excess glucose binds to free amino acids on tissue proteins or those in the circulation. The non-enzymatic glycosylation that occurs, results in the formation of Advanced Glycated End Products (AGEPs). Initially, these bonds are reversible and attach to the matrix components of the glomerulus or the GBM; later, these bonds become irreversible. The AGEPs can accumulate throughout the body's tissues as they are unable to be excreted due to the glomerular damage. Increasing amounts of AGEPs in tissues may result in microvascular complications [24]. Nitric oxide (NO) concentrations are reduced in a dose-dependent manner with the formation of AGEPs, exacerbating hypertension [25]. The advanced products then interfere with signal transduction. This may occur by changing soluble signals such as cytokines, hormones and free radicals. AGEPs are also known to be profibrotic in humans, interacting with the renin angiotensin system, cell signalling and RAGE, all disrupting the cellular matrix [26].

We therefore used glycated albumin as an advanced glycated protein to stimulate HK-2 cells to determine whether this would induce a different response in Fn production and whether this could be affected by stimulation with recombinant chemokines. The CCL18 effect 
Table 1 MTT assay of HK-2 cells in different experimental conditions and with or without co-stimulation with recombinant cytokines rCCL18 or rMCP-1 for $48 \mathrm{~h}$

\begin{tabular}{lll}
\hline $\begin{array}{l}\text { Condition with } 0 \mathrm{ng} / \mathrm{ml} \text { or } 20 \mathrm{ng} / \mathrm{ml} \\
\text { of recombinant cytokine stimulation }\end{array}$ & $\begin{array}{l}\text { MTT assay for HK-2 cells stimulated } \\
\text { without or with rCCL18 } \\
\text { Mean } \pm \text { SD }\end{array}$ & $\begin{array}{l}\text { MTT assay for HK-2 cells stimulated } \\
\text { without or with rMCP-1 } \\
\text { Mean } \pm \text { SD }\end{array}$ \\
\hline N0 & $0.664 \pm 0.024$ & $0.404 \pm 0.072$ \\
A0 & $0.331 \pm 0.040 * *$ & $0.107 \pm 0.029 *$ \\
M0 & $0.692 \pm 0.073$ & $0.390 \pm 0.005$ \\
H0 & $0.843 \pm 0.131$ & $0.603 \pm 0.033$ \\
N20 & $0.633 \pm 0.085$ & $0.517 \pm 0.059$ \\
A20 & $0.353 \pm 0.042 * *$ & $0.263 \pm 0.199$ \\
M20 & $0.590 \pm 0.113$ & $0.183 \pm 0.008$ \\
H20 & $0.758 \pm 0.057$ & $0.365 \pm 0.178$
\end{tabular}

Abbreviations: $N$ physiological glucose, $A$ glycated albumin, $M$ mannitol, $H$ high glucose

Legend to Table 2: The results from two independent experiments are shown. MTT assay were carried out for 3 wells with each of the cell culture conditions. The results are presented as mean \pm SD. The data were tested by Analysis of Variance with Bonferroni's correction for multiple comparisons. ${ }^{* *} p<0.01,{ }^{*} p<0.05$, in comparison to the cells culture in normal glucose concentration

on Fn production observed in high glucose was not seen with glycated albumin. These results suggested that the synergistic effects of CCL18 and high glucose concentration on Fn production are not dependent on stimulation of RAGE, or that the effect was limited by reduced viability of glycated albumin stimulation. The toxicity of albumin on proximal tubuloepithelial cells has previously been reported [27]. It appears that CCL18 or MCP-1, are unable to induce mechanisms to prevent the toxic effect of glycated albumin on these cells [28].

CCL18 is not produced by HK-2 cells (Montero unpublished data); however, these cells respond to CCL18 in a profibrotic manner. CCL18 has previously been described to be released from alternatively activated macrophages that contribute to idiopathic lung fibrosis [29, 30]. In addition, serum CCL18 has been described to be raised in patients with lung fibrosis [31], scleroderma [32], inflammatory diseases such as rheumatoid arthritis

Table 2 Number of viable HK-2 cells (assessed by trypan blue exclusion assay), in different experimental conditions with or without co-stimulation recombinant CCL18 for $48 \mathrm{~h}$

\begin{tabular}{ll}
\hline $\begin{array}{l}\text { Condition with } 0 \mathrm{ng} / \mathrm{ml} \text { or } \\
20 \mathrm{ng} / \mathrm{ml} \text { of recombinant } \\
\text { cytokine stimulation }\end{array}$ & $\begin{array}{l}\text { Number of live cells for HK-2 cells } \\
\text { stimulated without or with } \mathrm{rCCL} 18 \\
\text { (x1000 cells per well, Mean } \pm \text { SD) }\end{array}$ \\
\hline M0 & $288 \pm 17 * *$ \\
H0 & $467 \pm 22$ \\
M2O & $420 \pm 22$ \\
H2O & $437 \pm 43$ \\
\hline
\end{tabular}

Abbreviations: $\mathrm{M} 0=$ mannitol control + normal glucose, $\mathrm{H} 0=$ high glucose, $\mathrm{M} 20=$ mannitol + normal glucose $+20 \mathrm{ng} / \mathrm{ml} \mathrm{CCL18,} \mathrm{H20}=$ high glucose + $20 \mathrm{ng} / \mathrm{ml} \mathrm{CCL18}$. The number of viable cells were assessed by direct cell count with trypan blue exclusion assay. The results are presented as mean \pm SD. The data were tested by Analysis of Variance with Bonferroni's correction for multiple comparisons. The number of viable cells were lower in cells culture in the M0 group (**p $<0.01$ ), in comparison to the cells culture in other conditions. There was no significant differences in cell counts between $\mathrm{HO}, \mathrm{M} 2 \mathrm{O}$ and $\mathrm{H} 20$ groups
[33], acute lymphoblastic leukaemia [34] and gastric malignancies [35]. Inflammatory cells have been described to infiltrate the renal parenchyma in diabetic nephropathy in humans and also in rodent models [27, 36]. The ability of HK-2 cells to respond to CCL18 to alter the production of $\mathrm{Fn}$ in a high glucose environment, but not in physiological glucose, illustrates that the effect of a cytokine also depends on the metabolic environment.

Fn is an important matrix component that is detected in the glomeruli and tubulointerstitium of the kidneys during development and later in adulthood [37-39]. Proximal tubuloepithelial cells have previously been shown to produce Fn through activation of ERK, p38 MAPK, PKC $\alpha$ and PKC $\beta I$ signalling pathways [40]. Fn production may subsequently be increased further through its downstream activation of TGF- $\beta 1$, which leads to further fibrosis. Cell associated $F n$ has been reported to regulate cell-matrix interactions thereby stabilising the ECM $[41,42]$. In contrast, soluble Fn has more of an immunoregulatory role in murine tubuloepithelial cells, causing an increase in MCP-1 and macrophage inflammatory protein-2 via ERK and NF$\mathrm{kB}$ pathways [43]. The ability of HK-2 cells to produce variable amounts of Fn determined by their local environment illustrates the complexity of signalling pathways that may be induced or inhibited in association with different factors [44]. Further studies are needed to determine the underlying cell signalling pathways that result in an increase in Fn seen in HK-2 cells costimulated with CCL18 in high concentrations of glucose.

Urinary MCP-1 has been reported to be increased in patients with microalbuminuria and macroalbuminuria, with the latter predictive of progression of DN [21, 45]. This study showed no change in the production of Fn in HK-2 cells in a diabetic milieu with rMCP-1 co- 
stimulation. This would suggest that local production of MCP-1 may contribute to inflammatory cell recruitment but not directly to changes in the extracellular matrix, unlike CCL18.

This study has certain limitations. We examined protein levels of Fn but not mRNA levels in HK-2 cells, and thus could not distinguish between the different spliced forms of Fn (EDA+/-). Future experiments can be conducted to determine the predominant form of Fn produced. The findings from in-vitro studies may not be representative of in-vivo studies; however, there is no rodent equivalent of CCL18.

Despite the limitations of in-vitro cell culture, this work allows some insight into the pathogenesis of DN. The cytokines examined have been reported to be raised in patients with DN and albuminuria. The synergistic effect of CCL18 with high glucose to increase the production of Fn in HK-2 cells illustrates the importance and complexity of the roles of inflammatory, metabolic and fibrotic pathways. Understanding how these may interlink will help in the prevention of the progression of DN.

\section{Conclusion}

This study demonstrates that stimulation with chemokine CCL18 in high glucose upregulates the production of Fn from proximal tubuloepithelial cells. This may explain fibrotic changes in diabetic nephropathy. Further studies are required to elucidate the cell signalling events that induce these effects and correlate them with clinical findings.

\section{Acknowledgements}

We thank Professor Roger Mason, Imperial College London for the gift of HK-2 cells. Dr. Karen Molyneux, University of Leicester, for the methodology of the fibronectin assay.

\section{Funding}

Dr. Montero was supported by an Imperial College Renal and Transplant Centre Clinical Research Fellowship. Dr Tam was supported by the Diamond Fund from Imperial College Healthcare Charity. We are grateful for support from the NIHR Imperial Biomedical Research centre. The funding bodies were not involved in the design of the study, collection, analysis or interpretation of data nor in the writing of the manuscript.

\section{Availability of data and materials}

All data that support the conclusions were shown in detailed scattered plots in the figures. The HK-2 cell line is and experimental protocols are available to share with other interested researchers.

\section{Authors' contributions}

Conception or design, or analysis and interpretation of data, or both. (RM, $G B, C P, A F, F T)$. Drafting the article or revising it. (RM, CP, AF, FT). Providing intellectual content of critical importance to the work described. (RM, GB, CP, $A F, F T)$. Final approval of the version to be published. (RM, GB, CP, AF, FT).

\section{Competing interests}

RM and GB have no conflict of interest. FWKT has received research project grants from AstraZeneca Limited, Baxter Biosciences, Boehringer Ingelheim, and Medlmmune, and has consultancy agreements with Medlmmune and Rigel Pharmaceuticals. AHF has received research project grants from
Boehringer Ingelheim and has undertaken preparation of educational materials for AstraZeneca Limited, Boehringer Ingelfeim, Janssen and Merck. CDP has received a research project grant from GlaxoSmithKline and has a consultancy agreement with Amgen.

\section{Consent for publication}

None.

\section{Ethics approval and consent to participate}

No ethics approval or consent was required as this study used human cell-line culture based experiments.

Received: 12 September 2015 Accepted: 20 September 2016

Published online: 29 September 2016

References

1. Breyer JA, et al. Predictors of the progression of renal insufficiency in patients with insulin-dependent diabetes and overt diabetic nephropathy. The Collaborative Study Group. Kidney Int. 1996;50(5):1651-8.

2. Perkins $B A$, et al. Microalbuminuria and the risk for early progressive renal function decline in type 1 diabetes. J Am Soc Nephrol. 2007;18(4):1353-61.

3. Tervaert TW, et al. Pathologic classification of diabetic nephropathy. J Am Soc Nephrol. 2010;21(4):556-63.

4. Daniel C, et al. Thrombospondin-1 is an endogenous activator of TGF-beta in experimental diabetic nephropathy in vivo. Diabetes. 2007:56(12):2982-9.

5. Mason RM, Wahab NA. Extracellular matrix metabolism in diabetic nephropathy. J Am Soc Nephrol. 2003;14(5):1358-73.

6. Sanchez-Nino MD, et al. Beyond proteinuria: VDR activation reduces renal inflammation in experimental diabetic nephropathy. Am J Physiol Renal Physiol. 2012;302(6):F647-57.

7. Chen J, Chen JK, Harris RC. EGF receptor deletion in podocytes attenuates diabetic nephropathy. J Am Soc Nephrol. 2015;26(5):1115-25. doi:10.1681/ ASN.2014020192.

8. Gruden G, Perin PC, Camussi G. Insight on the pathogenesis of diabetic nephropathy from the study of podocyte and mesangial cell biology. Curr Diabetes Rev. 2005;1(1):27-40.

9. Herman-Edelstein $M$, et al. Dedifferentiation of immortalized human podocytes in response to transforming growth factor-beta: a model for diabetic podocytopathy. Diabetes. 2011;60(6):1779-88.

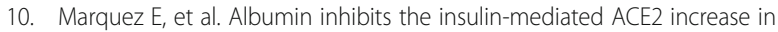
cultured podocytes. Am J Physiol Renal Physiol. 2014;306(11):F1327-34.

11. Ma J, et al. TLR4 activation promotes podocyte injury and interstitial fibrosis in diabetic nephropathy. PLoS One. 2014;9(5):e97985.

12. Gu L, et al. Fasudil inhibits epithelial-myofibroblast transdifferentiation of human renal tubular epithelial HK-2 cells induced by high glucose. Chem Pharm Bull (Tokyo). 2013:61(7):688-94.

13. Phillips $A O$, Steadman R. Diabetic nephropathy: the central role of renal proximal tubular cells in tubulointerstitial injury. Histol Histopathol. 2002; 17(1):247-52.

14. Navarro-Gonzalez JF, et al. Inflammatory molecules and pathways in the pathogenesis of diabetic nephropathy. Nat Rev Nephrol. 2011;7(6):327-40.

15. van Lieshout AW, et al. Enhanced interleukin-10 production by dendritic cells upon stimulation with Toll-like receptor 4 agonists in systemic sclerosis that is possibly implicated in CCL18 secretion. Scand J Rheumatol. 2009; 38(4):282-90.

16. Sayyed SG, et al. An orally active chemokine receptor CCR2 antagonist prevents glomerulosclerosis and renal failure in type 2 diabetes. Kidney Int. 2011;80(1):68-78.

17. Tesch $\mathrm{GH}$. Role of macrophages in complications of type 2 diabetes. Clin Exp Pharmacol Physiol. 2007;34(10):1016-9.

18. Alexandraki $\mathrm{K}$, et al. Inflammatory process in type 2 diabetes: The role of cytokines. Ann N Y Acad Sci. 2006;1084:89-117.

19. Navarro-Gonzalez JF, Mora-Fernandez C. The role of inflammatory cytokines in diabetic nephropathy. J Am Soc Nephrol. 2008;19(3):433-42.

20. Tang SC, Lai KN. The pathogenic role of the renal proximal tubular cell in diabetic nephropathy. Nephrol Dial Transplant. 2012;27(8):3049-56.

21. Tam FW, et al. Urinary monocyte chemoattractant protein-1 (MCP-1) and connective tissue growth factor (CCN2) as prognostic markers for progression of diabetic nephropathy. Cytokine. 2009:47(1):37-42.

22. Riser BL, et al. Urinary CCN2 (CTGF) as a possible predictor of diabetic nephropathy: preliminary report. Kidney Int. 2003;64(2):451-8. 
23. Qureshi A, P.C, Ahmad S, Frankel AH, Tam FWK. CCL18/PARC, a novel cytokine present in urine of diabetic patients, may be involved in regulation of inflammation and fibrosis in diabetic nephropathy. J Am Soc Nephrol. 2007:18:325A

24. Makita Z, et al. Advanced glycosylation end products in patients with diabetic nephropathy. N Engl J Med. 1991;325(12):836-42.

25. Zurbig $\mathrm{P}$, et al. Urinary proteomics for early diagnosis in diabetic nephropathy. Diabetes. 2012;61(12):3304-13.

26. Ban CR, Twigg SM. Fibrosis in diabetes complications: pathogenic mechanisms and circulating and urinary markers. Vasc Health Risk Manag. 2008:4(3):575-96.

27. Tang SC, Leung JC, Lai KN. Diabetic tubulopathy: an emerging entity. Contrib Nephrol. 2011;170:124-34

28. Caruso-Neves C, et al. PKB and megalin determine the survival or death of renal proximal tubule cells. Proc Natl Acad Sci U S A. 2006;103(49):18810-5.

29. Luzina IG, et al. Induction of prolonged infiltration of $T$ lymphocytes and transient T lymphocyte-dependent collagen deposition in mouse lungs following adenoviral gene transfer of CCL18. Arthritis Rheum. 2006;54(8): 2643-55.

30. Prasse A, et al. A vicious circle of alveolar macrophages and fibroblasts perpetuates pulmonary fibrosis via CCL18. Am J Respir Crit Care Med. 2006; 173(7):781-92.

31. Cai M, et al. CCL18 in serum, BAL fluid and alveolar macrophage culture supernatant in interstitial lung diseases. Respir Med. 2013;107(9):1444-52

32. Schutyser E, Richmond A, Van Damme J. Involvement of CC chemokine ligand 18 (CCL18) in normal and pathological processes. J Leukoc Biol. 2005; 78(1):14-26.

33. Vulcano $\mathrm{M}$, et al. Unique regulation of CCL18 production by maturing dendritic cells. J Immunol. 2003;170(7):3843-9.

34. Atamas SP, et al. Pulmonary and activation-regulated chemokine stimulates collagen production in lung fibroblasts. Am J Respir Cell Mol Biol. 2003; 29(6):743-9.

35. Leung SY, et al. Expression profiling identifies chemokine (C-C motif) ligand 18 as an independent prognostic indicator in gastric cancer. Gastroenterology. 2004;127(2):457-69.

36. Yonemoto $\mathrm{S}$, et al. Correlations of tissue macrophages and cytoskeletal protein expression with renal fibrosis in patients with diabetes mellitus. Clin Exp Nephrol. 2006;10(3):186-92.

37. Mounier F, Foidart JM, Gubler MC. Distribution of extracellular matrix glycoproteins during normal development of human kidney. An immunohistochemical study. Lab Invest. 1986;54(4):394-401.

38. Barnes $\mathrm{JL}$, et al. Expression of alternatively spliced fibronectin variants during remodeling in proliferative glomerulonephritis. Am J Pathol. 1995; 147(5):1361-71.

39. Eddy AA. Molecular basis of renal fibrosis. Pediatr Nephrol. 2000;15(3-4):290-301.

40. Yung $\mathrm{S}$, et al. Anti-dsDNA antibody induces soluble fibronectin secretion by proximal renal tubular epithelial cells and downstream increase of TGFbeta1 and collagen synthesis. J Autoimmun. 2015:58:111-22.

41. Sottile J, Hocking DC, Swiatek PJ. Fibronectin matrix assembly enhances adhesion-dependent cell growth. J Cell Sci. 1998;111(Pt 19):2933-43.

42. Sottile J, Hocking DC. Fibronectin polymerization regulates the composition and stability of extracellular matrix fibrils and cell-matrix adhesions. Mol Biol Cell. 2002;13(10):3546-59.

43. Ren $\mathrm{L}$, et al. Soluble fibronectin induces chemokine gene expression in renal tubular epithelial cells. Kidney Int. 2005;68(5):2111-20.

44. To WS, Midwood KS. Plasma and cellular fibronectin: distinct and independent functions during tissue repair. Fibrogenesis Tissue Repair. 2011;4:21.

45. Liu J, et al. Multiplex bead analysis of urinary cytokines of type 2 diabetic patients with normo- and microalbuminuria. J Immunoassay Immunochem. 2010;31(4):279-89.

\section{Submit your next manuscript to BioMed Central and we will help you at every step:}

- We accept pre-submission inquiries

- Our selector tool helps you to find the most relevant journal

- We provide round the clock customer support

- Convenient online submission

- Thorough peer review

- Inclusion in PubMed and all major indexing services

- Maximum visibility for your research

Submit your manuscript at www.biomedcentral.com/submit
Biomed Central 